Review

\title{
First Aid Education Guidelines for Peer Learning: The Approach in Practice
}

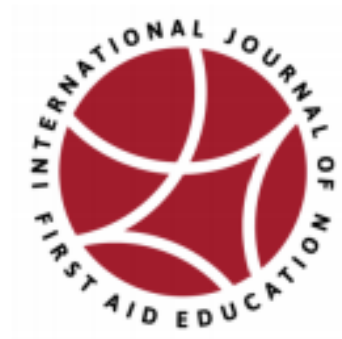

Kristopher Tharris ${ }^{1}$ and Joanna Muise ${ }^{2}$

${ }^{1}$ Learn. Change. Lead.

${ }^{2}$ Canadian Red Cross

\begin{abstract}
The International Federation of the Red Cross and Red Crescent (IFRC) updated its guidelines in 2020. The result of this process is the International First Aid, Resuscitation, and Education Guidelines 2020 (IFRC, 2020) that are grounded in the Chain of Survival Behaviors to support Red Cross and Red Crescent National Societies in effective implementation of first aid education. This paper is written by first aid educators as they reflect on the evidence expressed in the 2020 Guidelines and their own experience to provide opinion and contextual application to the educational approach of peer learning.

While peer learning is one tool in the toolbox that has an appropriate role for maximum effectiveness, it will not serve as a replacement for a facilitator. Peer learning can be very effective to ensure that the knowledge and skills explored in first aid education are adapted, contextualized, and locally implemented. In addition, humility is an important trait for the facilitator in that they must be comfortable in the unknown. By using peer learning, the facilitator is decentralizing the teaching, which can have both predictively positive and unintended or less desirable results. To mitigate the likelihood of unintended aspects, the authors suggest three stages to effectively implement peer learning approaches: the setup, ongoing support, and debriefing.

In this review of the Guidelines to inform contextual application, the limited evidence base available in creating the Guidelines is acknowledged and built upon by exploring learner groups that provide alternative forms of peer learning to those described (children and school-aged learners). Finally, this paper examines how peer learning is reflected in the Principles of First Aid Education (IFRC, 2020), particularly the principles which link to learners and discovery.
\end{abstract}

Key words: peer learning, cooperative learning, first aid education

\section{Introduction}

The International Federation of the Red Cross and Red Crescent (IFRC) updated the 2016 First Aid and Resuscitation Guidelines in 2020 to reflect the evidence regarding specific first aid clinical actions and uniquely paired evidence regarding first aid education. The result of this process is the International first aid, resuscitation, and education guidelines 2020 (IFRC, 2020), referred to in this review as the Guidelines. The approach was designed so that users of the Guidelines are easily able to apply them through adaptation to relevant learner contexts, contextualization to different levels of resources and medical care, and implementation through local strategies.

The development of each new guideline and the review of the 2016 edition included a new focus on the domains of the Chain of Survival Behaviors (IFRC 2016), see figure 1, as well as a fresh look through an 
educational lens across different contexts and the provision of education considerations for each first aid topic. This shift in emphasis occurred in response to calls from developers of curricula and first aid educators from across the Movement (including National Societies and the International Committee of the Red Cross (ICRC).

The process to include educational and contextual elements for each first aid topic was rigorous and consistent and is explained in full in the Guidelines. Individuals from 43 countries with clinical and/or educational expertise participated in teams to review existing literature to inform the educational approach to a first aid intervention for each topic. They also drew on their own experience and expertise. Together they then synthesized the insight available and contributed educational aspects to the Chain of Survival Behaviors for each first aid topic. In addition to the first aid topics, education reviewers looked specifically for papers which described and tested first aid education using different learning modalities and/or explored educational approaches in different contexts. Recommendations for education according to different learner needs were grouped across modalities where there was evidence to draw on, and contexts within which education needed to be adapted.

\section{Figure 1}

Chain of Survival Behaviors (IFRC, 2020, p. 35)

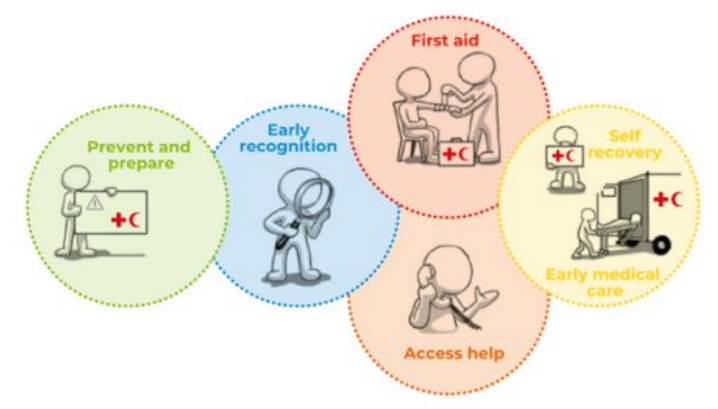

The Chain of Survival Behaviors is used by the Guidelines authors as a tool to emphasize how first aid education does not start and end with a first aid action, but begins with prevention through to supporting recovery. The domains of Prevent and prepare; Recognize; Provide first aid or Access help; and Support recovery, are fundamental considerations for education depending on the context and learner needs.
We write this paper as first aid educators with significant experience working in national and international first aid education. It contextualizes the foundational evidence as expressed in the Guidelines to provide additional practical implementation guidance from our own practice where there is an absence of evidence.

\section{Context Considerations}

The Peer Learning topic in the Guidelines breaks down peer learning into two categories: co-operative learning and peer-led learning. Each of these similar categories relies on the participants in a learning environment to take on additional responsibility for their own learning and that of a peer. The topic describes peer learning as a largely accessible modality due to the limited resources required for success. It is important to see peer learning as one tool in the toolbox that has an appropriate role for maximum effectiveness. However, it may not serve as a replacement for a facilitator. Peer learning can be very effective to ensure that the knowledge and skills explored in first aid education are fit for purpose; that is to say that a peer can likely link overall knowledge and skills much more effectively to context than an outsider. Recognizing these opportunities for us as facilitators is key to the success of peer learning approaches.

Educators dedicate significant time to set up, ongoing support, and debriefing when using peer learning as a teaching tool. We must develop self-awareness and embrace with flexibility new mindsets that relinquish some control over the learning environment and process. Developing these mindsets requires dedication to practice humility and openness to possibility. Schein and Schein (2018) describe a type of humble leadership in which the levels of relationship are parallel to those in a classroom:

-1. Impersonal domination

1. Transactional and rule-based

2. Cooperative and trusting

3. Emotionally intimate

While the extremes - level -1 and 3 - should have little place in a classroom, level 1 (transactional and rulebased) is often the default where the facilitator establishes the rules and provides knowledge and skills. 
In peer learning, we extend the quality of the relationships in the learning environment by pushing to level 2 where the facilitator views the learner as having existing knowledge and skills to share with peers, and trusts them to do so.

In addition to showing humility with regards to their own experience and knowledge, the facilitator must be comfortable in exploring the unknown. By using peer learning, the facilitator is decentralizing the teaching, which can have unintended results. These can be mitigated by having a strong sense of where the learners are starting from and the goal, all the while being flexible in the learning adventure to that goal. To achieve this intentional flexibility, we as educators identify three stages to effectively implement peer learning approaches: the setup, ongoing support, and debriefing.

The setup is where the facilitator sets the parameters for peer learning. The first element of the setup is ensuring that the facilitator has selected an appropriate knowledge/skill set for peer learning. Four criteria that can be used are:

1. The peer relationship brings significant value to the learning and themes.

For example, in assessment of the ill or injured person there are considerable differences between patients that peer learning could expose multiple perspectives and enhance a first aider's ability to assess more effectively. Conversely, exploring the different venoms found in wildlife in a specific country is highly technical and would likely be better served by another learning approach.

2. The application of knowledge or skills is particularly varied according to context.

For example, teaching a general approach to providing first aid varies considerably from an urban to remote environment and by having peers explore their own contexts it may broaden learners' understanding of the topic.

3. In working with peers, learners gain access to additional experiences and perspectives than would otherwise be possible working independently.
4. You have the time and the space to implement peer learning properly. This includes the time for setup and debriefing on your part as the facilitator, but also time for peers to develop some rapport and sense of trust.

The setup includes taking steps such as explaining the objectives and expectations, laying out the steps to follow, and encouraging participants to integrate their own experience to the activity. This leads to the stage of ongoing support where the facilitator is readily available to the learners to respond to and pose questions to help the learners remain on track with the learning objectives. At this point, the facilitator shifts their own approach towards coaching, leveraging tools like powerful questions, listening, and encouragement.

The last phase in peer learning - and by far the most important to us - is the debrief. Recognizing that in peer learning there will be quite a diversity of knowledge, skills, and applications that were explored, it is the responsibility of the facilitator to ensure that the learning is connected back to the course and learning objectives. This is the opportunity to assess knowledge and skills, redirect where necessary, and celebrate successes in the learning process.

With the right execution, peer learning invokes a higher order of learning. Consider Bloom et al.'s (1956) and Anderson et al.'s (2001) taxonomies of learning in relation to first aid: the majority of knowledge and skills in a first aid classroom reside at the knowledge/understanding level, with an overall analysis and application to specific situations. In order to effectively carry-out peer learning, as a base it requires learners to operate in the synthesis/evaluation zones to be able to effectively determine what information is important (analysis), package it for the peer (synthesis), and assess peers' understanding (evaluation).

Peer learning can be challenging to implement, evaluate effectiveness, and examine through research. There is not a universal approach to peer learning, much more a mindset on the part of the facilitator in using the approach. However, the potential for high-order, contextualized learning is immense, making this approach well-worth the investment in effective implementation. 


\section{Adaptations}

As facilitators, we need to be mindful that first aid care values and practices known and accepted by one group may not be by another. Learners may more favorably receive solutions and strategies offered by peers than those provided from outside the community. Peer learning encourages participants to reflect on the experience offered by their peers to consider their likeness while assessing desirable qualities. It is an incredibly flexible learning modality that can adapt to different durations of learning (very brief interventions and more in-depth interventions), different learner audiences (by age and role), or changes in the learning context. It is more inclusive than other learning modalities where participation is not enabled by technology or tools but through the peer relationship itself.

As practitioners, peer learning has allowed us to create authentic links between our own lived experiences and specific communities. As we have evolved as practitioners, so has our potential to be seen as a peer increasing in some spaces while narrowing in others. The literature used to support the Guidelines, while valuable, was often focused on peer learning that took place in school settings with young learners. We believe that the potential for applying peer learning in first aid education reaches far beyond this scope. It is important to remember; you may not be considered the peer to each of these learner audiences; you may instead be the 'guide on the side' who prepares and supports other facilitators in being the peer. Each of the following groups provide a unique example of how peer learning could be applied in different situations (no rank order among the examples), as well as specific topics from the Guidelines that could be explored using peer learning.

Group 1: Aging populations (senior citizens) may benefit from working with peers who better understand their physical or cognitive learning needs, for example, being mindful of how to adapt first aid care steps based on a change to their physical strength or balance, or choosing the language found commonly within their peer group. They may also benefit from a peer who authentically experiences the same type of injuries as they do and would have a similar perspective on prevention - such as when considering preventing trips and falls inside and outside of their home environment.
Alternatively, a younger facilitator may be well-liked by the group but may not understand their learning needs in the same way.

Group 2: In learning where gender has an influence. This peer relation could affect the physical learning space, for example, in instances where women and men are mindful of physical contact with one another. It could also affect the learning when cultural norms influence first aid care principles, for example, in instances where a woman's chest needs to be exposed to place AED pads and is thought to challenge her modesty. We don't suggest that facilitators cannot acknowledge gender differences but that there could be instances where learners are more comfortable working with a facilitator who identifies with the same gender.

Group 3: In communities where learners share a similar identity or role, have unique ways of knowing (generating and accepting knowledge), or a unique perspective on caregiving. For example - indigenous communities may have different norms to nonindigenous groups. Other groups that may benefit from working with a peer could include new parents, grandparents/caregivers, homeless persons, those struggling with substance use, law enforcement, disaster response personnel, etc. In the Guidelines, topics covered in the General approach (e.g., medical administration, de-escalation for violent behavior, psychological first aid) may benefit from a peer learning approach that is reflective of the unique identities of the learners.

Group 4: Those who live in a similar environment may find that this impacts their first aid learning themes or care steps based on their local context. For example, learners who live in urban communities compared to those who live in rural or remote communities, learners whose local environment experiences specific natural disasters, learners whose local environment involves conflict, etc. Each of these groups will have a unique access to resources and length of time before advanced care can arrive. Therefore, many topics will have a different response. For example, in a remote environment, caring for hypothermia will be different from caring in an urban environment where access to advanced medical care can be faster.

Group 5: Learners who self-identify into communities whose membership may influence their learning needs. 
For example, those whose religion influences their values towards providing care (a responsibility to act), or guides which care practices are accepted. Or groups whose participation in specific activities influences the content and context they will practice within, such as providing first aid while sailing or boating.

\section{Discussion}

Peer learning is reflected in the Principles of First Aid Education, particularly the principles of "link to learners" and "discovery" (IFRC, 2020, p.36).

The principle of linking to learners requires that the facilitator "consider all aspects of the learner group" (Guidelines, p.36) and adapt their approach to be relevant. This is a strong theme throughout the Guidelines, including in this topic. Linking to the learners is inherent in peer learning as the learners are in charge of their own learning. The element that the learner contributes is deep contextualization and application to a specific set of experiences, which ensure that the exchange is rooted in the direct experiences of the learners. This paves the way for effective application and integration of knowledge and skills to a learner's day to day life. As a facilitator, it is important to be cognizant of the inherent limitations to relying on peer learning for application: if the learner group is particularly homogeneous, the diversity of experiences will not be adequately reflected to prepare the learners for application to varied experiences. This is not particularly well explored in the Peer Learning topic due to the available evidence. For example, in the case that the learner group are all men, their own experiences might limit their ability to explore the experiences of other genders in relation to the application of a knowledge or skill. This highlights the importance of the last stage in implementing peer learning: the debrief. The debrief is the facilitator's opportunity to reconnect the learning experience to the intended objectives, broaden the scope of understanding, and solidify gained knowledge or skills.

The second principle-discovery- refers to allowing "time for learners to explore and reflect on what they have learned in order to develop their attitude and confidence to help" (IFRC, 2020, p. 36). Peer learning relies on discovery in that it allows the facilitator to individualize the learning experience through more intimate groupings of learners. This helps to create the space and time for learners to take a more exploratory approach to learning which also insists on more personal responsibility for learning. In taking responsibility for their own learning, there is a requirement for reflection in order to effectively apply their new-found understanding of knowledge and skills, which in turn supports the development of confidence.

The remaining principles are also well-reflected in the Peer Learning topic: peer learning ensures that a variety of experiences are built-in to the learning process, that there is common, easily understood language, and ample opportunity to seek clarity in the experience. The future of peer learning continues to build the approach by further aligning with these principles of first aid education.

\section{Practical implementation}

As authors reviewing this topic, here we take the opportunity to translate Guidelines into practice using our own experiences and insight.

Before considering the specific learning method best suited to your context (cooperative or peer-led), we encourage you to reflect on the local circumstances that will undoubtedly influence the peer learning relationship. The content of your learning intervention is only one small part of the equation. Asking yourself these questions will better prepare you to maximize peer learning's potential, regardless of whether you plan to use it within your personal practice or your organization's learning strategy. It is not an exhaustive list but a starting point for your reflection. There is no correct answer to these questions, and we expect that the answers will vary with each learner audience you support. In our experience, being mindful of these layers is essential for success and well worth the reflection time at the onset of your project.

- Most important is to identify what value the peer relationship brings to the learning and themes. What does a peer bring to the experience that a professional facilitator would (or could) not? Similarly, what could a peer bring to the experience that a teaching aid, such as a CPR feedback device, could not? 
- What factors allow someone to identify (by self or by others) as a peer? Can their likeness as a peer be constructed, or does it need to be inherent to be considered authentic? Is being a member of the same 'community' critical when acting as a peer?

- How will learners' expectations be managed? If there are peers in the room with varying levels of experience, is there a way to create parity in their likeness as peers?

- Does their likeness as a peer need to be highlighted to the learners to understand the benefit, or will they discover it for themselves? You may have groups of learners where the group itself is the same, or, you may have a group where the membership is diverse and you need to look for an element of similarity among the members.

Once you consider these layers, you are in a better position to decide if cooperative or peer-led learning is better suited to your context. If selecting peer-led learning, you will also need to consider the effort and resources required and available to you when preparing the peer facilitators. Preparing peers to lead a single session looks very different from building a sustainable network of peer facilitators.

Despite your best intentions, you may encounter learning interventions where the learners do not accept you as their peer. In our practice, we have experienced this when we have been older or younger than the learners, speak a different language, come from a diverse cultural background or another gender, or have a different lived experience (personally or professionally). Your reflection must consider how your similarities and differences will impact the learning intervention and your relationship. In some instances, you can continue as the facilitator, perhaps employing cooperative learning within the intervention. In other cases, you may discover that you can better serve the learners by shifting from being the 'sage on the stage to the guide on the side' and supporting one of their peers in leading. The key is to remain open and humble, recognizing that our likeness as a peer is a fluid concept that will change over time.

\section{Gaps}

While the evidence and expertise used to develop the Guidelines adheres well to the learning principles described, there are inevitably gaps in the evidence and recommendations which will continue to evolve. Here we set out the gaps that we identified which facilitators need to be aware of when developing their programs. Reflecting on the broad space that peer learning occupies and considering the learner audiences that could employ peer learning in the future, we believe that practitioner research needs to consider three additional streams of knowledge moving forward.

First, in addition to peer-led and cooperative learning, we believe that there could be a third application where peers work to construct knowledge together, for example by building scenarios around previous experiences and working together to figure out how to respond most effectively. In this instance, one peer is not formally leading the other, nor are they coaching one another's application. They are working together to construct understanding. Problem-based learning (Moust, 2021) and Case-based learning (Stanley, 2021) are theoretical approaches which might be considered for peer-led learning which are not covered by the Guidelines and it would be important for future versions of the Guidelines to explore if and how they might be considered. Both approaches can draw on previous experiences of learners to develop skills and confidence to act effectively.

Second, the literature reviewed for the guidelines focused on developing learners' knowledge and practical skill. We would like to see peer learning further explored for its potential to impact learners' attitudes and values linked to first aid and resuscitation education, such as the willingness to act.

Finally, given the rapid and large-scale adoption of virtual learning in 2020, we wish to further understand the application of peer learning by exploring how it is impacted by peers being remote from one another. In addition to the necessary technology reducing inclusivity, does it change the peer relationship or alter the connection that peers commonly experience with one another in person? This remains to be seen. 


\section{Conclusion}

Peer learning as an educational approach holds a great deal of potential to enhance the learning experience in first aid training. The literature used to support the Guidelines, while valuable, tends to focus on peer learning in school settings with young learners. As practitioners, we believe that the potential for applying peer learning in first aid education reaches far beyond this scope. Across a range of learner audiences, through careful consideration, planning, and execution, educators are able to build on the foundations of knowledge and experience of each learner in the experience to create learning opportunities that reflect the intent of the Guidelines: experience that is adapted, contextualized, and locally implemented.

\section{Acknowledgements}

We wish to thank the reviewers, writers and editors that were involved in the development of the 2020 Guidelines.

\section{Conflict of Interests}

No financial conflict of interest exists for any of the authors. The authors were content contributors to the International first aid, resuscitation, and education guidelines 2020.

\section{Corresponding Author}

Dr. Kristopher Tharris kristopher@learnchangelead.com

\section{References}

Anderson, L.W., Krathwohl, D.R., Airasian, P.W., Cruikshank, K.A., Mayer, R.E., Pintrich, P.R., Raths, J., Wittrock, M.C. (2001). A Taxonomy for Learning, Teaching, and Assessing: A revision of Bloom's Taxonomy of Educational Objectives. New York: Pearson, Allyn \& Bacon.

Bloom, B., Engelhart, M. D., Furst, E. J., Hill, W. H., \& Krathwohl, D.R. (1956). Taxonomy of Educational Objectives and Handbook 1: Cognitive Domain. Longmans, Green and Co LTD.

International Federation of Red Cross Red Crescent Societies. (2016). International First Aid and Resuscitation Guidelines 2016. https://www.globalfirstaidcentre.org/resource/2016-first-aidinternational-guidelines/

International Federation of Red Cross Red Crescent Societies. (2020). International first aid, resuscitation, and education guidelines 2020. https://www.globalfirstaidcentre.org/resource/international-first-aid-resuscitation-andeducation-guidelines-2020-2/

Moust, J., Bouhuijs, P., \& Schmidt, H. (2021). Features of problem-based learning. In J. Moust, P. Bouhuijs, \& H. Schmidt (Eds.) Introduction to Problem-based Learning (pp. 9-18). Routledge.

Schein, E.H. \& Schein, P.A. (2018). Humble leadership: the power of relationships, openness, and trust. Berrett-Koehler.

Stanley, T. (2021). Case Studies and Case-based Learning. Routledge 